DOI 10.37882/2223-2982.2020.04.39

\title{
СИСТЕМА ПОДГОТОВКИ ВОЖАТОГО К ЭФФЕКТИВНОМУ ОБЩЕНИЮ В УСЛОВИЯХ ДЕТСКОГО ОЗДОРОВИТЕЛЬНОГО ЛАГЕРЯ
}

\section{SYSTEM FOR PREPARING A COUNSELOR FOR EFFECTIVE COMMUNICATION IN A CHILDREN'S HEALTH CAMP}

\section{E. Shcherbakova T. Shcherbakova}

Summary: This article addresses to a new, but always very acute problem facing any teacher - the experience of communicating with children. We narrowed down this problem somewhat, examined the issues of communication in the conditions of a children's recreation camp, when teachers are far away, there is no direct parental attention, however, the educational process in the camp continues to the full extent. Highly qualified, well-trained counselors and educators, real masters of their craft, can give children a lot in terms of their development, personal development and socialization in just one camp shift. We consider the teacher's ability to communicate with children competently and professionally to be the basis of the entire pedagogical process. In this article, we tried to highlight different areas of communication in a children's health camp: between teachers and children, between members of the teaching staff themselves, between teachers and parents. We touched upon the issue of communication between teachers and the administration. We tried to answer the question of how to organize a conflict-free environment in the camp on the basis of productive communication, how to make sure that each child is provided with the most comfortable conditions away from home and close people. The author describes his own experience in training counselors to master their skills of communication culture, pedagogical ethics and tact.

This article may be useful for students of pedagogical universities. Everyone who is preparing to work in a children's health camp as a counselor and educator. The materials of the article can be successfully used in courses for improving professional skills, for all practical teachers and interested persons.

Keywords: pedagogical communication, children's recreation camp, interaction culture, pedagogical ethics, image of the teacher, game activity, ethical training, morality, pedagogical tact, team.
$\mathrm{B}$ ажнейшим компонентом подготовки студентов педагогических вузов является организация разных видов практик. Летняя педагогическая практика является одной из них. Эта практика особая. Подготовка к ней в Московском городском педагогическом университете начинается задолго до ее непосредственного начала: читаются соответствующие тематические

\author{
Щербакова Елена Викторовна, \\ К.п.н., дочент, Московский городской педагогический \\ университет \\ elena08041966@yandex.ru \\ щербакова Татьяна Николаевна, \\ К.п.н., доцент, Московский городской педагогический \\ университет \\ aleks170573@yandex.ru
}

Аннотация: Представленная статья обращена к не новой, но всегда очень остро стоящей перед любым педагогом проблеме - опыту общения с детьми. Мы несколько сузили эту проблему, рассмотрели вопросы общения в условиях детского оздоровительного лагеря, когда учителя далеко, нет прямого непосредственного родительского внимания, однако, воспитательный процесс в лагере продолжается в полной мере. Высококвалифицированные, хорошо подготовленные вожатые и воспитатели, настоящие мастера своего дела за одну только лагерную смену могут многое дать детям в плане их развития, личностного становления и социализации. Основой всего педагогического процесса мы считаем умение педагога грамотно и профессионально общаться с детьми. В представленной статье мы попытались осветить разные направления общения в детском оздоровительном лагере: между воспитателями и детьми, между самими членами педагогического коллектива, между педагогами и родителями. Затронули вопрос общения педагогов с администрацией. Мы попытались ответить на вопрос, как, на основе продуктивного общения, организовать бесконфликтную среду в лагере, как сделать так, чтобы каждому ребенку обеспечить наиболее комфортные условия в отрыве от дома и близких людей. Отдельно описан собственный опыт подготовки вожатых по овладению ими навыков культуры общения, педагогической этики и такта.

Статья может быть полезна студентам педагогических вузов. Всем, кто готовится трудиться в детском оздоровительном лагере в качестве вожатого и воспитателя. Материалы статьи могут с успехом быть использованы на курсах совершенствования профессионального мастерства, всем педагогампрактикам, заинтересованным лицам.

Ключевые слова: педагогическое общение, детский оздоровительный лагерь, культура взаимодействия, педагогическая этика, имидж педагога, игровая деятельность, этический тренинг, нравственность, педагогический такт, коллектив.

теоретические учебные курсы, проводятся практические занятия, где отрабатываются необходимые навыки и формируются соответствующие компетенции. В рамках традиционной ежегодной «Недели вожатского мастерства» будущие вожатые погружаются в атмосферу жизни летнего лагеря, проходя ежедневно множество «маршрутов» разноплановой и разнонаправленной 
подготовки. Лучшие педагоги вуза и опытные бывалые вожатые дают мастер-классы, где учат буквально всему, что может пригодиться летом в лагере: петь, танцевать, рисовать, развлекать, заниматься спортом, выдерживать большие физические и психологические нагрузки, обеспечивать безопасность детей, разрешать конфликты и многому еще другому. Однако особое внимание уделяется формированию у студентов умения грамотного педагогического общения, освоению законов педагогической этики и такта. Это совсем не случайно. Ведь в профессиональной организации общения кроется секрет педагогического успеха, поскольку оно создает прочный фундамент профессионального мастерства. Это отмечалось в разные годы всеми отечественными и зарубежными педагогами, среди которых назовем только несколько имен: Ш.А. Амонашвили, В.А. Сластенин, Януш Корчак, А.С Макаренко, В.А. Сухомлинский, К.Д. Ушинский, Н. Е. Щуркова и др.

Под педагогическим общением вслед за А.А. Леонтьевым, мы понимаем профессиональное общение педагога и воспитанников, направленное на создание комфортного психологического климата в коллективе, создающее оптимальные доверительные отношения между всеми участниками образовательного процесса. [5]

На наш взгляд, владение законами эффективного общения необходимо, прежде всего, для формирования комфортного для каждого ребенка психологического климата, создания дружеских межличностных отношений в отряде и всем коллективе детского лагеря. Мастерство вожатых и воспитателей строится на том, чтобы владеть необходимым в каждой ситуации стилем, тоном общения с детьми, коллегами, родителями, администрацией. В условиях оторванности ребенка от семьи, родителей, привычной для себя обстановки это особенно необходимо и важно.

Мы не ставим в этой статье своей задачей подробное описании стилей педагогического общения. Они известны и хорошо описаны в педагогической литературе. $[4,7,9]$ Стилем педагогического общения мы считаем индивидуальные особенности взаимодействия и детей. [7, 8, 9]

Назовем основные стили общения, описанные в наиболее авторитетных общепризнанных публикациях: авторитарный, демократический, либерально-попустительский, общение, основанное на увлечении совместной творческой деятельностью, общение-дистанция, заигрывание. Обычно педагог сам вырабатывает собственный неповторимый стиль общения в процессе практики взаимодействия с детьми и опытом. Нельзя говорить о том, что тому или иному педагогу свойстве- нен тот или иной стиль общения. Обычно педагог- мастер умеет «играть» с разными стилями, варьирует их в зависимости от ситуации, от собственных личностных качеств, от индивидуальных особенностей отдельного ребенка и коллектива. Что хорошо для одного педагога, оказывается неприемлемым для другого.

Однако, мы однозначно негативно можем оценивать применение попустительство, неоправданное заигрывание с ребенком, излишний авторитаризм и императивность поведения.

Визитной карточкой педагога и одной из главных составляющих общения является речь.

Приведем основные характеристики грамотной речи. Речь должна быть:

- правильной - соответствовать существующим на данный момент литературно-языковым нормам;

- точной - ясно выражать мысль говорящего человека;

- доступной и простой - слушатели должны легко понимать ее;

- логичной - соответствовать законам логики;

- красивой - когда говорящий использует все разнообразие языковых средств, средств выразительности и образности, отсутствие шаблонов;

- лаконичной - лишенной ненужных повторов и лишних слов;

- дикция ясная и четкая, точное воспроизведение звуков;

- чистой - в которой нет нелитературных слов, жаргонизмов и вульгаризмов, ненужных заимствований;

- благозвучной - та, где имеется гармония звуков, мелодичность, приятная для слуха человека.

К речевым недостаткам мы относим:

- монотонность - неспособность человека дифференцировать изменения голоса по высоте, малый голосовой диапазон, бедность тембра, отсутствие мелодичности;

- плохая артикуляция в силу зажатости нижней челюсти, «гудящий голос»;

- резкие голосовые перепады, то очень высокое, то резко низкое звучание, без плавных переходов;

- гнусавый голос, вызванный вялостью произношения и «ленивым» языком;

- недостаточная сила звука, тихий голос, низкая его полётность;

- бедность тембральной окраски, отсутствие абертонов, эмоциональная «неокрашенность» голоса; 
- скорость, ритмика речи может быть слишком замедленной, или же слишком быстрой. Отсутствие ритмических пауз в речи.

При подготовке вожатых к работе в детском лагере мы обращаем внимание так же на невербальный язык общения. Это важно, поскольку несловесные знаки (поза, жесты, мимика) передают большой объем информации. Есть мнение, что невербально передается от 60 до 80 \% всей информации.

В процессе общения оказывается важным то, что порой кажется мелочами: как двигаются руки педагога. Какова его походка, мимика, выражение глаз, поза, осанка, умеет ли он улыбаться, устанавливать визуальный контакт, какая у педагога прическа и одежда, носит ли он украшения, есть ли у него татуировки и т.д.

Все это способствует установлению доверительного контакта с детьми. На подготовительных занятиях мы выполняем множество упражнений на отработку невербальной коммуникации. Предлагаемые практические задания отвечают на вопросы: как ходить? Какая должна быть улыбка? Можно ли прикасаться к ребенку, обнимать его, целовать? Как пользоваться ароматами духов?

После подобных тренингов студенты осознают, что:

- осанка вожатого должна быть красивой и выразительной. Тогда дети видят его собранным, уверенным, обладающим внутренней силой и достоинством;

- жесты свои желательно сдерживать, иначе можно кого-то даже травмировать, не нужно суетиться без меры;

- мимика так же должна быть в меру подвижной;

- взгляд открыт, доброжелателен, располагает к общению. Глаза педагога во время разговора должны смотреть на собеседника;

- своим внешним поведением вожатый не несет детям свое плохое настроение, проблемы и неурядицы;

- желательна «открытая поза», располагающая к контакту и совместным делам;

- не следует нарушать личностное пространство ребенка. Это создает эмоционально-психологическое напряжение;

- Форма одежды вожатого должна соответствовать обстановке (парадная, спортивная, для отдыха). В любом случае одежда должна быть чистая, аккуратная.

Совместно со студентами мы создаем Кодексы законов (правила) общения в детском лагере на разных уровнях. Выглядят они примерно так:

\section{1. Кодекс общения вожатого с детьми:}

1. Не обсуждайте с детьми личностные качества членов педагогического отряда и административных работников, это может негативно сказаться на их авторитете;

2. Не устраивайте соревнования с другими вожатыми на тему: « Кого больше любят дети?»

3. Помните свое собственное детство. Это поможет лучше понять мотивы поступков ребенка, его поведение;

4. Не читайте детям длинных и нудных нотаций;

5. Подходить к каждому ребенку только с позиций Добра и Любви;

6. Главное наше оружие - улыбка, искренняя доброжелательность и справедливость, юмор;

7. Не выделяй в отряде «любимчиков», которым многое позволено;

8. Покажи ребенку, что любой его неблаговидный поступок не повод для ругани, но он расстраивает и огорчает Вас;

9. Любое свое требование аргументируй, убеждай в необходимости его выполнения;

10.Любую возникающую проблему решаем спокойно, без нервов и суеты;

11. Умей признать свои ошибки и неправоту перед воспитанниками. Умей спокойно воспринимать конструктивную критику в свой адрес;

12. Сохраняй детские секреты, не используй полученную информацию против самого ребенка, цени его доверие к Вам;

13. Категорически невозможно использовать при детях ненормативную лексику, оскорбительный жаргон;

14. Не задавай ребенку нетактичных вопросов;

15. Не давай пустых обещаний, которые, ты знаешь заранее, не сможешь выполнить. Старайся общаться с детьми честно;

16. Как можно чаще хвали ребенка, умей искренне порадоваться его успехам. Хвалить ребенка можно даже авансом;

17. Не делай замечания при других членах отряда. Все проступки старайся обсуждать наедине с ребенком;

18. Умей разглядеть детские проблемы и беды, чтобы своевременно придти ему на помощь;

19. Не допускай панибратских, фамильярных отношений в общении с воспитанниками, не прибегай к непродуктивному стилю заигрывания;

20. Опираемся только на положительное в человеке, хорошего много в каждом ребенке. Нужно только это разглядеть;

21. Категорический запрет на побои ребенка, унижение его как личности.

22. Всегда помнить о том, что главная ценность в жизни - это сам Человек! 
2. Кодекс общения с родителями

1. При общении с родителями соблюдайте максимальную вежливость и тактичность, корректность;

2. В рамках общения с родителями обязательно обращаться к ним исключительно по имени и отчеству;

3. Не предъявлять никаких императивных требований к родителям;

4. Все свои требования и пожелания давайте в виде советов;

5. Любой разговор с родителями начинайте с похвалы ребенка, с его положительных качеств, с его хороших поступков. И только потом переходите на проблемы, если они имеют место быть;

6. Умейте убедить родителей, что Вы их союзник, Вы вместе решаете детские проблемы. Вы защитник ребенка, а не враг его.

7. Научитесь внимательно слушать и слышать родителей.

8. Не жалуйтесь на ребенка;

9. Разговоры с родителями о проблемах ребенка ведите только в его отсутствии;

10. Даже если у Вас возникают напряженные отношения с родителями, непонимание, этого не должен чувствовать ребенок. Он не должен пострадать от этого.

3. Кодекс общения администрацией летнего лагеря 1. Не следует пытаться руководить администрацией, пытаться внушить руководству, что именно Ваша точка зрения является единственно верной;

2. Не разговаривайте с администрацией категоричным императивным тоном;

3. Все свои предложения выдвигайте уверенно, но тактично и вежливо;

4. Не будьте подхалимом, не жалуйтесь начальству на своих коллег. Ваши коллеги этого не оценят

5. Руководство должно понимать, Вы человек ответственный, что на Вас можно положиться. Вам можно доверить любое дело. Вы не подведете.

6. Обращайтесь с любым вопросом к своему непосредственному руководителю. Никто не оценит Ваше обращение через «голову руководства» .

7. Ко всем сотрудникам лагеря обращайтесь исключительно по имени, отчеству и на «Вы»;

8. Не путайте личные и рабочие отношения;

9. Старайтесь всегда выполнять данные обещания;

10. Не принято на работе рассказывать о своем здоровье, о личных проблемах и переживаниях.

4. Кодекс отношений с коллегами

1. Помните, что Вы - единая команда, которая делает общее важное и ответственное дело;

2. Учитывайте мнение сотрудникам по возникающим вопросам. Прислушивайтесь к более опытным коллегам.

3. При возникновении конфликта постарайтесь понять точку зрения оппонента. Пытайтесь найти точки соприкосновения.

4. Следует предпринять все усилия, чтобы подружиться и найти общий язык с напарником по отряду (вторым вожатым, воспитателем). Это послужит на пользу делу воспитания детей. Постарайтесь справедливо совместно распределить обязанности.

5. Оказывайте коллегам посильную помощь и моральную поддержку.

После проведения летней педагогической практики мы ежегодно проводим опрос студентов на тему: «Помогли ли Вам занятия, тренинги, мастер-классы, проведенные в университете, строить эффективное общение в детском оздоровительном лагере?» Результаты такого опроса показали, что из опрошенных 130 студентов, практически все 100\% дали положительный ответ. В заключение мы хотим сказать, что летняя педагогическая практика для студента - это ступень профессионального становления и первые шаги к профессиональному мастерству. Студент получает возможность осмысливать теоретический багаж, полученный на занятиях в вузе, увидеть и оценить опыт своих коллег, оценить самого себя в деле. Педагогическое общение, как один из важных составляющих педагогической деятельности, приобретает особое значение при организации летнего оздоровительного отдыха детей. Поэтому, помимо вооружения студентов вузов прочными теоретическими и практическими психолого-педагогическими знаниями, технологиями игровой деятельности, умением в короткие сроки создавать детский коллектив отряда и лагеря, способностью обеспечивать безопасную среду и разрешать конфликты, проводя многие другие компоненты подготовки, огромное внимание отводится формированию умений грамотно общаться на разных уровнях. Именно это умение, на наш взгляд, является самым главным во всей педагогической деятельности, определяющим ее успех и результаты. 


\section{ЛИТЕРАТУРА}

1. Арсенина Е.Н. «Возьми с собою в лагерь: Игры, викторины, конкурсы, инсценировки, развлекательные мероприятия». Серия: В помощь воспитателям и вожатым. - 2007, 183 с.

2. Вайндорф-Сысоева М.Е. «Основы вожатского мастерства» Учебно-методическое пособие. - М: «Центр гуманной литературы», 2005. - 160 с.

3. Рассел, Джесси Детский лагерь / Джесси Рассел. - М.: Книга по Требованию, 2012. - 127 с.

4. Кан-Калик В.А. Учителю о педагогическом общении: Кн. Для учителя. - М.: Просвещение, 1987. - 290 с.

5. Леонтьев А.А. Педагогическое общение / Под ред. М.К. Кабардова. 2-е изд., перераб. и доп. М.; Нальчик, 1996. - 367 chttp://kounb.kurganobl.ru/cgi-bin/ irbis64r_13/cgiirbis_64.exe?LNG=\&Z21ID=\&I21DBN=CKC\&P21DBN=CKC\&S21STN=1\&S21REF=3\&S21FMT=fullwebr\&C21C0M=S\&S21CNR=20\&S21P01=0\&S2 $1 P 02=0 \& 521 P 03=M=\& S 21 S T R=$

6. Танченко Т.С. Воспитание духовно-нравственных ценностей у подростка в условиях внешкольной деятельности (из опыта работы организации скаутов г. Ивантеевка, Московской области) // Наука и современность — 2011. — № 8-1. — С. 340-341.

7. Щербакова Е.В. Щербакова Т.Н. Имиджелогия для современного педагога. / Щербакова Т.Н., Щербакова Е.В. Учебно-методическое пособие / Москва, УЦ Перспектива, 2012.— 201 с.

8. Щербакова Е.В., Щербакова Т.Н. Организация временного коллектива в детском оздоровительном лагере / Проблемы современного педагогического образования. 2017. № 56-3. С. 266-275.

9. Щербакова Е.В., Щербакова Т.Н. Способы формирования профессионального имиджа современного учителя / Проблемы современного педагогического образования. 2018. № 60-1. С.411-415

10. Щуркова, Н.Е. Жизнь и воспитание: учебное пособие / Н.Е. Щуркова. — Москва: Издательство Юрайт, 2020. - 139 с.

11. Щуркова, Н.Е. Педагогические технологии : учебное пособие для академического бакалавриата / Н.Е. Щуркова. — 3-е изд., испр. и доп. — Москва : Издательство Юрайт, 2019. — 232 с

12. Якиманская, И.С. Основы личностно ориентированного образования / И.С. Якиманская. - М., 2011. - 220с.

( ) Щербакова Елена Викторовна (elena08041966@yandex.ru), Щербакова Татьяна Николаевна (aleks170573@yandex.ru)

Журнал «Современная наука: актуальные проблемы теории и практики»

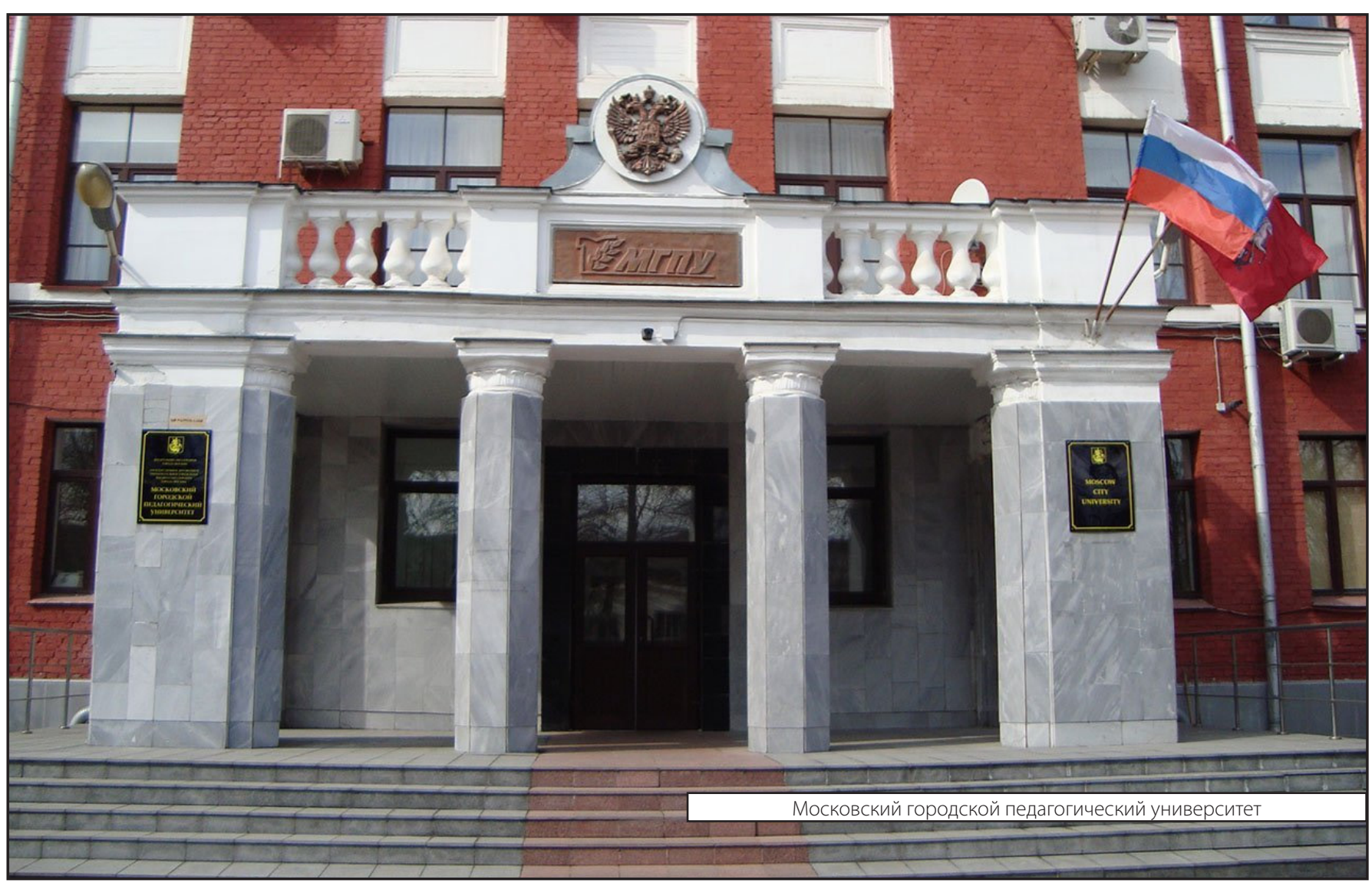

